\title{
Properties of Whey-Protein-Coated Films and Laminates as Novel Recyclable Food Packaging Materials with Excellent Barrier Properties
}

\author{
Markus Schmid, ${ }^{1}$ Kerstin Dallmann, ${ }^{1}$ Elodie Bugnicourt, ${ }^{2}$ Dario Cordoni, ${ }^{3}$ Florian Wild, ${ }^{1}$ \\ Andrea Lazzeri, ${ }^{3}$ and Klaus Noller ${ }^{1}$ \\ ${ }^{1}$ Fraunhofer Institute for Process Engineering and Packaging IVV, Giggenhauser Straße 35, 85354 Freising, Germany \\ ${ }^{2}$ Innovació i Recerca Industrial i Sostenible (IRIS), Parc Mediterrani de la Tecnologia, Avenida Carl Friedrich Gauss No. 11, \\ 08860 Castelldefels, Spain \\ ${ }^{3}$ Department of Chemical Engineering, Industrial Chemistry and Materials Science, University of Pisa, Via Diotisalvi No. 2, \\ 56126 Pisa, Italy \\ Correspondence should be addressed to Markus Schmid, markus.schmid@ivv.fraunhofer.de
}

Received 5 November 2011; Revised 16 March 2012; Accepted 16 March 2012

Academic Editor: Jan-Chan Huang

Copyright () 2012 Markus Schmid et al. This is an open access article distributed under the Creative Commons Attribution License, which permits unrestricted use, distribution, and reproduction in any medium, provided the original work is properly cited.

In case of food packaging applications, high oxygen and water vapour barriers are the prerequisite conditions for preserving the quality of the products throughout their whole lifecycle. Currently available polymers and/or biopolymer films are mostly used in combination with barrier materials derived from oil based plastics or aluminium to enhance their low barrier properties. In order to replace these non-renewable materials, current research efforts are focused on the development of sustainable coatings, while maintaining the functional properties of the resulting packaging materials. This article provides an introduction to food packaging requirements, highlights prior art on the use of whey-based coatings for their barriers properties, and describes the key properties of an innovative packaging multilayer material that includes a whey-based layer. The developed whey protein formulations had excellent barrier properties almost comparable to the ethylene vinyl alcohol copolymers (EVOH) barrier layer conventionally used in food packaging composites, with an oxygen barrier (OTR) of $<2\left[\mathrm{~cm}^{3}(\mathrm{STP}) /\left(\mathrm{m}^{2} \mathrm{~d}\right.\right.$ bar) $]$ when normalized to a thickness of $100 \mu \mathrm{m}$. Further requirements of the barrier layer are good adhesion to the substrate and sufficient flexibility to withstand mechanical load while preventing delamination and/or brittle fracture. Whey-protein-based coatings have successfully met these functional and mechanical requirements.

\section{Introduction}

High demands are put on packaging material, especially in the food industry, in order to preserve the quality of the packed good throughout its lifecycle. Protection against oxygen is one determining factor that guarantees the maximum shelf life of food products [1].

The requirements of packaging material are specific to the type of food to be packed; materials need to fulfil different needs in terms of light, moisture, water vapour, and gas barriers. Appropriate levels of oxygen and carbon dioxide, packing atmosphere, and respiration rate have to be taken into account to optimally preserve the packed food, avoid colour or taste deviation, oxidation of grease, formation of microorganisms, damaging of nutrients, and so forth $[2,3]$. Figure 1 summarizes and quantifies the barrier requirements of selected food and pharmaceuticals [4].

To achieve these requirements, expensive multilayer coextruded or laminated plastic films are widely used in the packaging industry in order to combine the respective technofunctional properties the polymers $[2,5-7]$. These films often make use of ethylene vinyl alcohol copolymers (EVOH) to create a sufficient oxygen barrier. Polymers used for those applications are petroleum based and their combination 


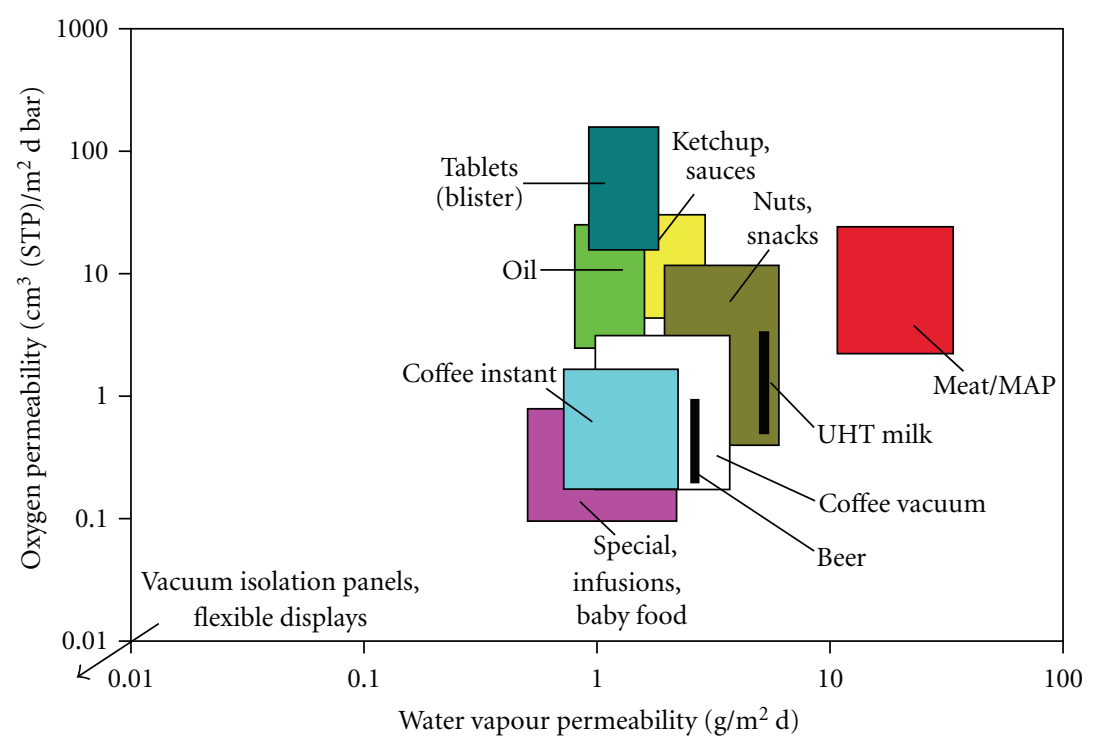

FIGURE 1: Barrier requirements of selected food and pharmaceuticals.

in various layers hampers recyclability as monomaterials of high purity are needed for reprocessing [8]. Thus, research into sustainable packaging materials that maintain the performance of composite structures has recently intensified. The current study (WHEYLAYER project, http:// www.wheylayer.eu/) is a research project targeted at developing sustainable packaging solutions. As the whey-proteincoatings are biodegradable, the resulting multilayer films can offer greatly improved recyclability. Furthermore, as opposed to many renewable materials, which normally do not provide sufficient barriers, the whey protein coating has the potential to extend the shelf life of food by virtue of its intrinsic barrier properties against gases like oxygen [9-12].

Among proteins that could be used in the field of packaging, especially for food sensitive to water and gas permeation, whey is one of the most promising. Whey is a byproduct of cheese manufacturing that contains approximately $7 \%$ dry matter. In general the dry matter includes $13 \%$ proteins, $75 \%$ lactose, $8 \%$ minerals, about 3\% organic acids, and less than $1 \%$ fat. Whey protein can be separated and purified from the liquid whey in an efficient membrane filtration process and subsequent spray drying to obtain either Whey Protein Concentrate (WPC, average protein concentration $65-80 \%$ in dry matter) or Whey Protein Isolate (WPI, highly pure grade with concentrations over $90 \%$ in dry matter). In general these whey proteins are used as additives in the agrofood industry, such as the athletic drinks [12]. Nevertheless, whey is in abundant supply; data from the International Whey Conference 2008 shows that $40 \%$ of the 50 million tonnes of whey produced annually in Europe are still unprocessed, which makes it an interesting resource in view of its excellent oxygen barrier properties [13].

Whey protein coatings were already tested as edible films on, among others, peanuts, salmon, fruits, or cereals, whereby whey coating offered good aroma, fat, humidity, and oxygen barriers. It could be shown that they helped to improve the shelf life of, for example, peanuts, by retarding the lipid oxidation causing rancidity [14]. In addition, those edible films were reported not to modify the sensory attributes of the coated good or its aspect, while providing some health benefits for the consumer [15].

Numerous authors have reported potential uses for whey protein in the packaging field, emphasizing in particular its good barrier properties, especially for its use as a coating on paper [16, 17], but also on plastic substrates [18-22]. Indeed, whey coatings on polypropylene (PP), polyvinylchloride (PVC), and low-density polyethylene (LDPE) demonstrated excellent visual properties, such as excellent gloss and high transparency, as well as good mechanical properties $[17,23]$.

Finally, it was also shown that it was possible to process whey-based formulations for packaging applications and edible coatings through extrusion as well as compression molding. Research has shown the importance of suitable conditions to control denaturation and cross-linking as well as the benefits of whey mixed with other plant proteins $[15,24,25]$.

However, the incorporation of plasticizing agents was generally reported as necessary to overcome the intrinsic brittleness of whey protein coatings [10, 14]. Glycerol and sorbitol were commonly used plasticizers for this purpose $[14,18,26]$. Plasticizers enhance the mobility of polymer chains through an increase in intermolecular spacing and thus lead to films with enough flexibility to keep their integrity once applied and subsequently formed. However, use of plasticizers has the disadvantage of lowering barrier properties [14, 22, 27].

Whey proteins can be hydrolyzed by different enzymes, such as protease, in specific conditions [15]. Similarly, the present study confirmed, in the case of multilayer configuration, that resulting coatings could be biodegraded using enzymatic detergent [22, 28]. This makes multilayer 
films recyclable, since the separation of the layers made up of conventional petroleum-based plastics and associated by the whey-based layer is facilitated, enabling them to be handled separately. As an alternative, the multilayer packaging incorporating a whey-based barrier layer can be composted when using biodegradable polymeric substrates. Overall, use of whey-based layers could reduce $\mathrm{CO}_{2}$ emissions and consumption of resources in packaging production [28].

\section{Materials and Methods}

2.1. Materials. Whey protein isolate (WPI), BiPro of Davisco Foods International (Le Sueur) (dry protein pureness 97.4\%; $\mathrm{N} \times 6.38$ ), was used for formulating the whey-based coatings in the present study. Glycerol and sorbitol used as plasticizer were supplied by Merck Schuchardt OHG (Hohenbrunn) and Merck KGkA (Darmstadt), respectively. Polyethylene terephthalate (PET) films of $50 \mu \mathrm{m}$ and $12 \mu \mathrm{m}$ thickness (Melinex of DuPont Teijin Films, SA) were used as substrate for whey protein coating application. Resulting coated films were laminated with polyethylene (PE) film of $20 \mu \mathrm{m}$ thickness as a sealing layer, with Liofol UK 3640/UK 6800 by Henkel KGaA (Düsseldorf) used as an adhesive.

2.2. Formulation Preparation. Besides using BiPro, different types of whey proteins were isolated by membrane filtration in order to obtain pure whey protein with suitable film forming properties. Various modification techniques, like chemical modification, enzymatic hydrolysis, and highpressure treatment were evaluated to improve film-forming behaviour [13].

As shown in the literature $[9,13,20,22,25,29,30]$, the denaturation of the proteins is essential to achieving the necessary barrier properties. Denaturation leads to a protein network via disulphide bonds, hydrogen bonds, and hydrophobic and electrostatic interactions, which furthermore allows the formation of proper whey protein films $[15,31]$.

Thus, standard denatured protein formulations were prepared by heating aqueous WPI solutions $(10 \% \mathrm{w} / \mathrm{w})$ to $90^{\circ} \mathrm{C}$ for $30 \mathrm{~min}$ (above their denaturation temperature of around $58-60^{\circ} \mathrm{C}$ as measured by DSC) using an electronic stirrer with heating, Thermomix 31-1, from Vorwerk Elektrowerk $\mathrm{GmbH} \& \mathrm{CoKG}$ (Wuppertal). After cooling the solutions to room temperature in a water bath, glycerol $(66.7 \%$ on dry matter, dm) or sorbitol ( $100 \%$ on $\mathrm{dm}$ ) was added and stirred for another $30 \mathrm{~min}$ (at $200 \mathrm{rpm}$ ). Degassing was performed via ultrasonication in each stage.

2.3. Coating and Curing. The WPI coating formulations were applied on corona pretreated PET films (thickness $12 \mu \mathrm{m}$; surface energy $>40 \mathrm{mN} / \mathrm{m}$ ). At lab scale, a control coater, Erichson GmbH \& CoKG (Hemer), was used to apply the solution evenly at a speed of $4 \mathrm{~m} / \mathrm{min}$. Depending on the kind of grooved rod used, film wet coating thicknesses varying between 10 and $30 \mu \mathrm{m}$ were achieved. Coated polymer films were dried in an oven, Kelvitron T 6120 from Heraeus
Thermo Electron Corporation (Langenselbold), at $105^{\circ} \mathrm{C}$ for $10 \mathrm{~min}$.

Pilot plant trials were performed on a lacquering and laminating plant. Corona-discharge-treated PET films $(12 \mu \mathrm{m})$ were coated with whey protein solution by use of a comma bar roller coaster system and laminated with PE $(20 \mu \mathrm{m})$. Whey protein layers of up to $10 \mu \mathrm{m}$ could be achieved.

2.4. Fast Screening of Formulations Based on Mechanical and Optical Properties. The properties of coated films were characterized using a light microscope, Diaplan of Leitz (Incident light; 200-fold zoom-in), in terms of aspect (transparency), brittleness, scratch resistance, and surface finish after mechanical stress. Therefore, a method according to a rating scale was implemented. The 4 criteria were rated according to 5 levels $(5=$ best result). For each formulation investigated for performance, films of $40 \times 15 \mathrm{~mm}$ were prepared. In order to analyze resistance of the coating against mechanical stress, one piece of each film was twisted aboutface $\left(180^{\circ}\right)$ four times. For analysis of scratch resistance, films were scratched 7 times using a standardized brush (angle approximately $40^{\circ}$ ). Samples were then analyzed regarding scratches or damage and classified according to the aforementioned rating scale.

2.5. Thermomechanical Properties. For the Dynamic Mechanical Thermal Analysis (DMTA), the samples coated and uncoated (coating removed by biodegradation) were used to evaluate the elastic modulus of the total structure and of the substrate.

The width of the sample was $10 \mathrm{~mm}$ and the thickness varied for each sample. The load cell used was $100 \mathrm{~N}$ and a pretension was applied. The temperature scans were carried out from 0 to $250^{\circ} \mathrm{C}$ with a heating rate of $5^{\circ} \mathrm{C} / \mathrm{min}$ and a frequency of $1 \mathrm{~Hz}$.

2.6. Adhesion. The bond strength measurement method measures the interlaminar strength that keeps together two different surfaces and was applied to the laminate samples (PET/WHEYLAYER/Adhesive/PE). The equipment is composed by the same machine and the same clamps used as those for the common tensile and tear test (sample holder according to EN ISO 4624 and EN ISO 527-1). For each test, two samples with dimensions of $100 \mathrm{~mm}$ per $15 \mathrm{~mm}$ were prepared and cut according to either the machine or the transverse direction. The two surfaces were then supposed to split up for a length of $40 \mathrm{~mm}$ and be kept in constant conditions of $23^{\circ} \mathrm{C}$ and $50 \%$ relative humidity. The ends of the samples were positioned into the clamps of the tensile machine and the bond strength was measured. The number of the sample for each trial was more than 10 to ensure statistically reliable results.

In addition to that, the adhesion between the whey layer and the substrate was measured according to the International Standard EN ISO 4624:2002, paints, varnishes and plastics (pull-off test). This standard evaluates the adhesion/cohesion of a single or a multilayer coating system 
(for paints, varnishes, and other kinds of coating materials) by the application of perpendicular tensile stress on the substrate and measuring the minimum value of stress that causes the material to detach or rupture. The samples have a round stick area with a diameter of $20 \mathrm{~mm}$. The load is applied orthogonally at the plane of the coated substrate. The specimens were pulled with a constant speed of $0.5 \mathrm{~mm} / \mathrm{min}$. The load was recorded until the sample broke. The test was carried out in constant conditions of $23^{\circ} \mathrm{C}$ and $50 \%$ of relative humidity. Every surface must be scratched with sandpaper and cleaned with acetone before the application of the glue.

2.7. Optical Properties. Film transparency is known to be an important feature for the packaging industry. First, qualitative evaluation was done visually using human cognition; this was then complemented by the quantitative measurement of light transmittance of the films using the spectral photometer PMQ 3 Carl Zeiss (Grosskuchen) with a wavelength of $600 \mathrm{~nm}$ (to correlate with the visible eye perception).

2.8. Barrier Properties. Oxygen permeability of PET films coated with the previously described whey-based formulations was measured according to DIN 53380-3 (DIN, 1998) at $23^{\circ} \mathrm{C}$ and $50 \% \mathrm{RH}$ using an Ox-Tran $2 / 20$. The coated side of the films was exposed to flowing oxygen gas and the other side to flowing nitrogen gas. Resulting oxygen permeability of multilayer films was deduced in terms of $\mathrm{cm}^{3} / \mathrm{m}^{2} \cdot \mathrm{d} \cdot \mathrm{bar}$ and used for further calculations regarding permeability of the single whey protein layer. A WPI-coated polymer film can be considered as a 2-layer-structure, comparable to a laminated material $[9,17]$. The following equations can be used:

$$
\begin{gathered}
\frac{d}{P}=\frac{d_{1}}{P_{1}}+\frac{d_{2}}{P_{2}}, \\
\frac{1}{Q_{\text {tot }}}=\sum \frac{d_{i}}{p_{i}}=\frac{1}{Q_{1}}+\frac{1}{Q_{2}}+\frac{1}{Q_{3}}+\cdots,
\end{gathered}
$$

where $d$ represents the thickness of each layer, $i,\left(d=\Sigma d_{i}\right)$ and $P$ is the oxygen permeability of each layer. Subscript 1 stands for the polymer film and subscript 2 for the WPI coating on the surface.

Oxygen permeability values of whey-based coatings are converted to a thickness of $100 \mu \mathrm{m}\left(Q_{100}\right)$ in order to allow direct comparison of different materials independently of the coating thickness. Film thicknesses were measured with the instrument Mahr Millimar C1216 of Mahr GmbH (Göttingen) after oxygen transmission tests. WPI coating thickness was calculated by subtracting the base for PET film. Five random positions on the film were measured and averaged.

\section{Results and Discussion}

3.1. Fast Screening of Formulations. In light of the prior art previously reported, the whey-based layer formulations were developed in order to reach the best compromise between

\begin{tabular}{|c|c|}
\hline Designation & Type of protein/modification \\
\hline w1 & $\mathrm{pH} 6 /(10 \% \mathrm{w} / \mathrm{w})$ \\
\hline w2 & $\mathrm{pH} 3 /(15 \% \mathrm{w} / \mathrm{w})$ \\
\hline w3 & $\mathrm{pH} 7 /(8 \% \mathrm{w} / \mathrm{w})$ \\
\hline w4 & Acetylated $/ 5 \%$ anhydride \\
\hline w5 & Acetylated $/ 10 \%$ anhydride \\
\hline w6 & Succinylated/5\% anhydride \\
\hline w7 & Succinylated $/ 10 \%$ anhydride \\
\hline w8 & Hydrolyzed $/ 0.5 \%$ Alcalase $\mathrm{DH}=6$ \\
\hline w9 & Hydrolyzed $/ 0.5 \%$ Alcalase $\mathrm{DH}=9.5$ \\
\hline w10 & $\mathrm{pH} 3 /(15 \% \mathrm{w} / \mathrm{w})$ \\
\hline w11 & $\mathrm{pH} 7 /(10 \% \mathrm{w} / \mathrm{w})$ \\
\hline $\mathrm{w} 12$ & $\mathrm{pH} 3 /(8 \% \mathrm{w} / \mathrm{w})$ \\
\hline
\end{tabular}

TABle 1: Different types/modifications of whey protein used.

DH: degree of hydrolysis.

barrier properties and flexibility [9-11, 17, 21, 31-33]. As mentioned in Section 2, different types of whey protein were used and formulated with variable amounts of different additives (marked w1-w12 in Table 1 and Figure 2).

The nature and amount of plasticizer were varied in order to obtain films with good integrity and flexibility while containing as little plasticizer as possible so as not to jeopardize barrier performance. The film properties, as assessed through the previously explained rating scale in terms of the 4 criteria of interest, are reported in Figure 2. Aside from $\mathrm{w} 6$ and $\mathrm{w} 12$, the scratch resistance of the formulations tested is rather low, but such a coating may still be suitable as an intermediary layer in a multilayer configuration. This analysis resulted in the determination of the most suitable formulations for the target and for further testing.

3.2. Optical Properties. The transparency of the films was measured by light transmittance using the spectral photometer PMQ 3 Carl Zeiss (Grosskuchen). The transmittance spectrum was recorded over the whole wavelength range $(250-1000 \mathrm{~nm})$. As shown in Figure 3, no difference in light transmittance was observed between pure PET and coated PET (over the whole spectrum and especially at $600 \mathrm{~nm}$ ). All the samples reached a transmittance over $90 \%$ and appeared transparent, even though a slight haze could be recognized by the eye.

3.3. Thermo-Mechanical Properties. Isolating the value of the elastic modulus of PET and considering its contribution in the modulus of the total structure made it possible to calculate the Young's Modulus of the coating. The Young's Modulus, $E$, of the whey-based layer was determined applying the theory of composite materials in "isodeformation conditions" [34]: the load applied during the DMTA analysis on the coated sheet leads to a uniform deformation on the different layers of the material and the interface between the two different layers remains unchanged. Using the "rule of the mixtures of binary composites," it is possible to calculate 


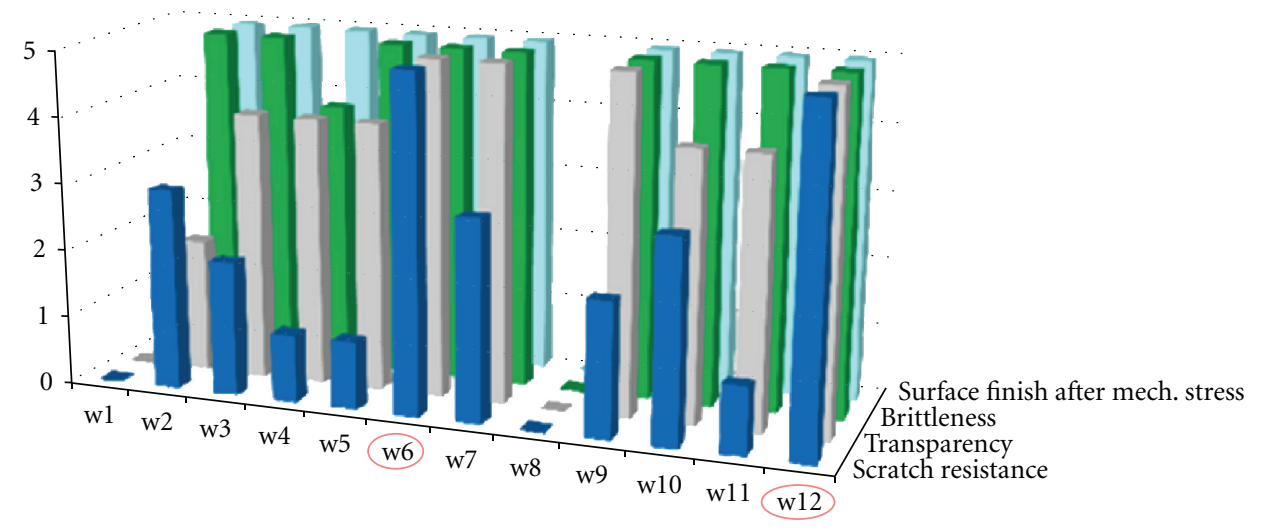

FIGURE 2: Mechanical and optical properties of different whey-based coating formulations screened according to a rating scale (0-5).

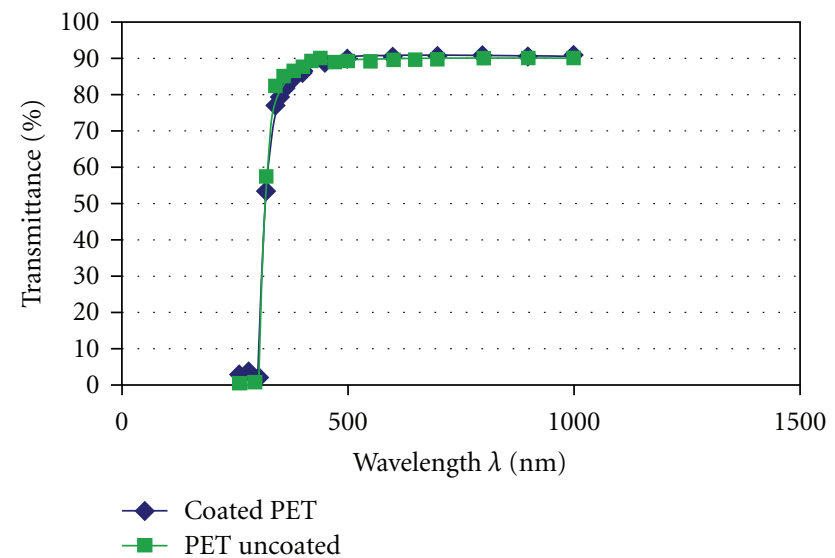

FIGURE 3: Transmittance spectrum of uncoated and whey-coated PET.

the elastic modulus of a composite material when the elastic modulus of the matrix and the fibres and their volume fractions are known.

Thus, the DMTA tests allowed the modulus of the wheybased layer to be calculated. The tests showed that the layer is much stiffer than the substrate used and it is possible to observe that it contributes to increasing the rigidity of the coated film (Figure 4). The high stiffness of the whey-based layer could be related to the high cross-linking density of the structure formed by the proteins.

3.4. Adhesion. Using the laminate bond strength method, it was not possible to separate the layers since the substrate (PET) broke at 5.5-6 N/15 mm earlier. Therefore the adhesion measurement method according to the International Standard EN ISO 4624:2002 (pull-off test) was performed.

Results of the pull-off test showed that whey-based coating displays excellent adhesion to the corona pretreated substrates on which it was applied. Resulting peeling forces were over the standard and only cohesive failures in the substrates were observed, as opposed to adhesive fractures at the whey-based layer/substrate interface. The two surfaces separated at the level of coextruded PET and thus

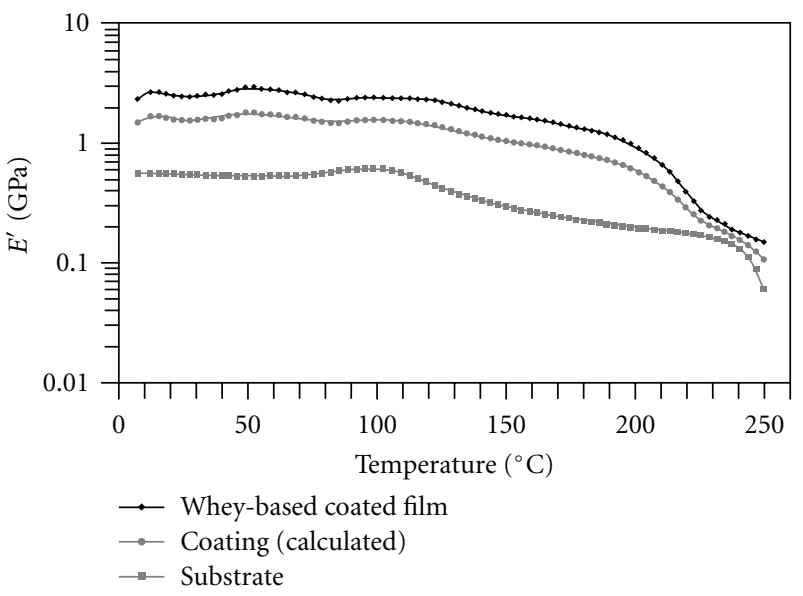

Figure 4: Comparison of the evolution of Young's modulus versus temperature of whey-based coated films, coating (determined applying the theory of composite materials in "isodeformation conditions") and substrate.

appeared clear and shiny. The average value of strength $\sigma$ was $15 \mathrm{~N} / \mathrm{mm}^{2}$.

3.5. Barrier Properties. As expected, it was shown that formulations with higher plasticizer content had lower barrier properties.

Indeed, due to the increase of the mobility of the polymer chains between cross-links, diffusion coefficient $D$ and solubility coefficient $S$ increase. Consequently, the permeation coefficient, as defined in (2) below, also increases:

$$
P=D \cdot S .
$$

This directly influences the permeability of the polymer, which is directly proportional to the diffusion coefficient, as described by

$$
Q=\frac{P}{d} .
$$

Nevertheless, with the optimum plasticizer content and for the formulation selected according to the previously 


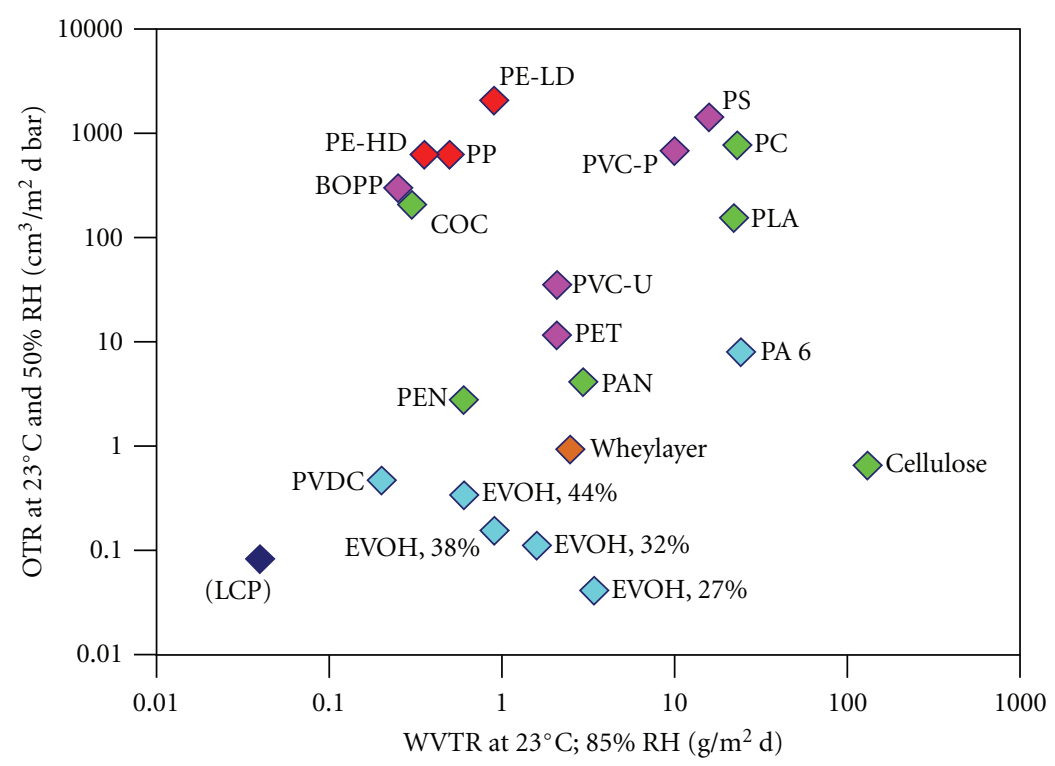

FIGURE 5: Barrier properties of whey-based layer versus other plastics commonly used in the packaging industry.

described scale method, barrier properties in the range of OTR $Q_{100}=1-2\left[\mathrm{~cm}^{3}(\mathrm{STP}) / \mathrm{m}^{2} \mathrm{~d}\right.$ bar $]$ and of WVTR $Q_{100}=2-3\left[\mathrm{~g} / \mathrm{m}^{2} \mathrm{~d}\right]$ could be achieved (see Figure 5 ). This confirmed that the dense crosslinked protein network provided high barrier properties and therefore confirmed the potential of the whey-coating to replace $\mathrm{EVOH}$ with average ethylene contents. Referring to Figure 4, these barrier values demonstrate the potential of whey-based coated laminates to be used even for quite demanding food stuffs, in terms of oxygen and water vapour barrier requirements, such as meat, and snacks, sauces.

\section{Conclusion}

For the optimized whey-based formulations developed in the present study, their high transparency without surface defect, temperature stability, mechanical performance, and flexibility, along with their adhesion on the substrates, made them suitable for packaging applications. A whey protein layer is able to serve as a good oxygen barrier and can either be used as an upper layer or as a sandwich layer in a composite, as the lamination tests showed it is possible to obtain proper composites with whey-proteincoated polymer films. Depending on its position in the multilayer, the whey-based layer (seal or interim layer) has to meet different demands. Therefore a suitable formulation can be chosen according to factors such as the packed good, product shelf life, or consumer demands. Whey proteins are thus a promising resource for the packaging industry in that they provide a sustainable, recyclable packaging material that meets all the performance requirements of packaging materials.

\section{Acknowledgment}

The authors wish to acknowledge the funding from the European Community's Seventh Framework Programme
(FP7/2007-2013) for the research leading to these results under Grant Agreement no. 218340-25 entitled WHEYLAYER.

\section{References}

[1] G. L. Robertson, Food Packaging: Principles and Practice, Food science and technology, Taylor \& Francis/CRC Press, Boca Raton, Fla, USA, 2nd edition, 2006.

[2] K. Petersen, P. V. Nielsen, G. Bertelsen et al., "Potential of biobased materials for food packaging," Trends in Food Science and Technology, vol. 10, no. 2, pp. 52-68, 1999.

[3] V. K. Haugaard, A. M. Udsen, G. Mortensen, L. Hoegh, K. Petersen, and F. Monahan, "Potential food applications of biobased materials. An EU-concerted action project," StarchStarke, vol. 53, no. 5, pp. 189-200, 2001.

[4] H. C. Langowski, "Permeation durch Lebensmittelverpackungen-Anwendungsbeispiele," in Permeation durch Packstoffe, Institut für Verfahrenstechnik und Verpackung, Freising, Germany, 2008, Fraunhofer IVV.

[5] S. Sängerlaub, D. Gibis, E. Kirchhoff, M. Tittjung, M. Schmid, and K. Müller, "Compensation of pinhole defects in food packages by application of iron-based oxygen scavenging multilayerFilms," Packaging Technology and Science. In press.

[6] K. Mueller, C. Schoenweitz, and H. C. Langowski, "Thin laminate films for barrier packaging application-influence of down gauging and substrate surface properties on the permeation properties," Packaging Technology and Science, vol. 25, no. 3, pp. 137-148, 2012.

[7] S. K. Swain and A. I. Isayev, "Effect of ultrasound on HDPE/clay nanocomposites: rheology, structure and properties," Polymer, vol. 48, no. 1, pp. 281-289, 2007.

[8] H. J. Endres and A. Siebert-Raths, Engineering Biopolymers: Markets, Manufacturing, Properties, and Applications, xvi, Hanser, Cincinnati, Ohio, USA, 2011.

[9] S. I. Hong and J. M. Krochta, "Oxygen barrier performance of whey-protein-coated plastic films as affected by temperature, relative humidity, base film and protein type," Journal of Food Engineering, vol. 77, no. 3, pp. 739-745, 2006. 
[10] M. Schmid, G. Bischur, F. Wild, and K. Noller, "Whey coated plastic films to replace expensive polymers and increase recyclability," in Proceedings of the 12th Tappi European Place Conference, Tappi, Budapest, Hungary, May 2009.

[11] M. Schmid, J. Held, and F. Wild, "Thermoforming of whey protein-based barrier layers for application in food packaging," Food Science \& Technology, vol. 25, no. 3, pp. 34-35, 2011.

[12] C. H. P. Onwulata, "Whey processing, functionality and health benefits," in IFT Press Series; Variation: IFT Press Series, WileyBlackwell, Ames, Iowa, USA, 2008.

[13] E. Bugnicourt, M. Schmid, O. M. Nerney, and F. Wild, "Wheylayer: the barrier coating of the future," Coating International, vol. 43, no. 11, pp. 7-10, 2010.

[14] K. Khwaldia, C. Ferez, S. Banon, S. Desobry, and J. Hardy, "Milk proteins for edible films and coatings," Critical Reviews in Food Science and Nutrition, vol. 44, no. 4, pp. 239-251, 2004.

[15] C. I. H. Onwulata and J. Peter, Whey Processing _Functionality and Health Benefits, vol. 1, Wiley-Blackwell, Ames, Iowa, USA, 2008.

[16] M. Gällstedt, "Films and composites based on chitosan, wheat gluten or whey proteins - their packaging related mechanical and barrier properties," in Fibre and Polymer Technology Department, KTH, Stockholm, Sweden, 2004.

[17] S. I. Hong and J. M. Krochta, "Whey protein isolate coating on LDPE film as a novel oxygen barrier in the composite structure," Packaging Technology and Science, vol. 17, no. 1, pp. 13-21, 2004.

[18] J. W. Lee, S. M. Son, and S. I. Hong, "Characterization of protein-coated polypropylene films as a novel composite structure for active food packaging application," Journal of Food Engineering, vol. 86, no. 4, pp. 484-493, 2008.

[19] R. Sothornvit, D. S. Reid, and J. M. Krochta, "Plasticizer effect on the glass transition temperature of beta-lactoglobulin films," Transactions of the American Society of Agricultural Engineers, vol. 45, no. 5, pp. 1479-1484, 2002.

[20] K. L. Dangaran and J. M. Krochta, "Preventing the loss of tensile, barrier and appearance properties caused by plasticiser crystallisation in whey protein films," International Journal of Food Science and Technology, vol. 42, no. 9, pp. 1094-1100, 2007.

[21] T. H. McHugh and J. M. Krochta, "Sorbitol-plasticized vs glycerol-plasticized whey protein edible films: integrated oxygen permeability and tensile property evaluation," Journal of Agricultural and Food Chemistry, vol. 42, no. 4, pp. 841-845, 1994.

[22] M. Schmid and V. Jost, "Biopolymers in paper and film applications," in Speciality Plastic Films, Maack Business Services, Düsseldorf, Germany, 2010.

[23] M. Ozdemir and J. D. Floros, "Optimization of edible whey protein films containing preservatives for mechanical and optical properties," Journal of Food Engineering, vol. 84, no. 1, pp. 116-123, 2008.

[24] C. I. Onwulata, S. Isobe, P. M. Tomasula, and P. H. Cooke, "Properties of whey protein isolates extruded under acidic and alkaline conditions," Journal of Dairy Science, vol. 89, no. 1, pp. 71-81, 2006.

[25] M. Schmid, F. Wild, and K. Agulla, "All the whey," in The Packaging Professional, The Institute of Materials, Minerals and Mining, London, UK, 2010.

[26] M. Schmid, K. Agulla, and F. Wild, "Barriere aus Biomaterial-Molkenprotein als Basis für vielversprechende Folienbeschichtung," in Lebensmitteltechnik, LT Food Medien, GmbH, Hamburg, Germany, 2010.
[27] R. Sothornvit and J. M. Krochta, "Water vapor permeability and solubility of films from hydrolyzed whey protein," Journal of Food Science, vol. 65, no. 4, pp. 700-703, 2000.

[28] P. Cinelli and A. Lazzeri, "Le proteine nel settore degli imballaggi Wheylayer. Bio-Imballaggio derivato dal siero del latte," in Biopolpack, 2010, Parma, Italy.

[29] K. S. Miller and J. M. Krochta, "Oxygen and aroma barrier properties of edible films: a review," Trends in Food Science and Technology, vol. 8, no. 7, pp. 228-237, 1997.

[30] R. Sothornvit and J. M. Krochta, "Plasticizer effect on oxygen permeability of beta-lactoglobulin films," Journal of Agricultural and Food Chemistry, vol. 48, no. 12, pp. 62986302, 2000.

[31] T. H. McHugh, J. F. Aujard, and J. M. Krochta, "Plasticized whey protein edible films - water vapour permeability properties," Journal of Food Science, vol. 59, no. 2, 1994.

[32] S. I. Hong and J. M. Krochta, "Oxygen barrier properties of whey protein isolate coatings on polypropylene films," Journal of Food Science, vol. 68, no. 1, pp. 224-228, 2003.

[33] M. Schmid, J. Held, and K. Noller, "Innovative concepts for food packaging," Packaging Films, vol. 2, pp. 8-12, 2011.

[34] W. F. Smith and H. Javad, Scienza e Tecnologia die Materiali, McGraw-Hill, 3rd edition, 2008. 

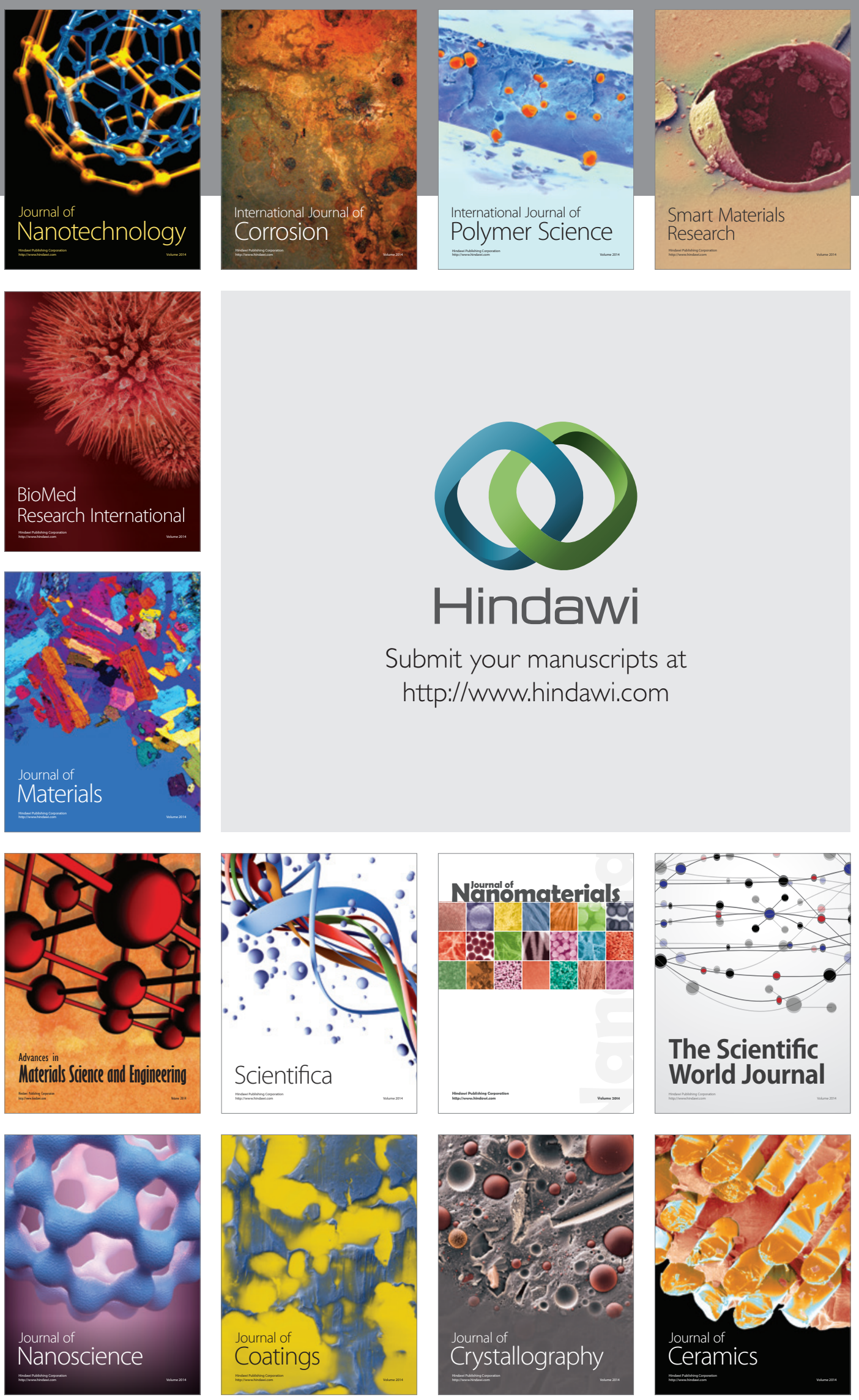

The Scientific World Journal

Submit your manuscripts at

http://www.hindawi.com

\section{World Journal}

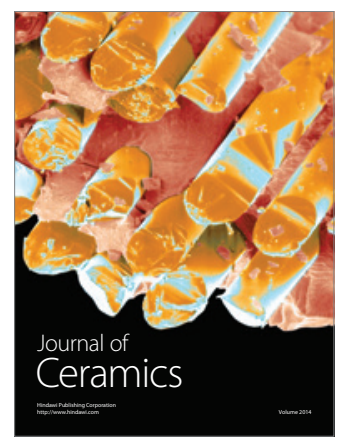

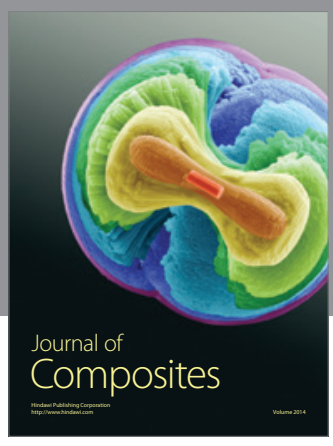
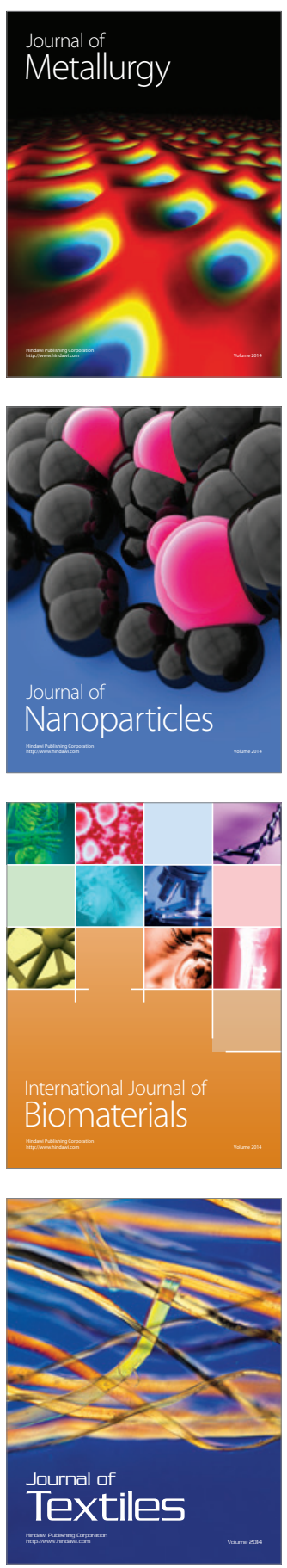